\title{
CDISC SDTM Medical Evaluator Terminology
}

National Cancer Institute

\section{Source}

National Cancer Institute. CDISC SDTM Medical Evaluator Terminology. NCI Thesaurus.

Code C96777.

Terminology associated with the medical evaluator codelist of the Clinical Data

Interchange Standards Consortium (CDISC) Study Data T abulation Model (SDT M). 